\title{
Spontaneous rupture of hepatocellular carcinoma
}

\author{
Amer Hawatmeh ${ }^{1}$, Khalid Jumean ${ }^{1}$, Ahmed Abu Arqoub ${ }^{1}$, Hamid Shaaban ${ }^{2}$ \\ ${ }^{1}$ Department of Internal Medicine, St. Michael's Medical Center, Newark, NJ 07102, USA. \\ ${ }^{2}$ Department of Internal Medicine, Hematology and Oncology, St. Michael's Medical Center, Newark, NJ 07102, USA.
}

\begin{abstract}
This is a very interesting case of a 64-year-old female with a history of chronic hepatitis $\mathrm{C}$ infection, with abdominal pain and was found to have ruptured hepatocellular carcinoma (HCC). She was managed with the two-stage therapeutic approach first using transarterial embolization to provide adequate hemostasis and then surgical resection with an excellent outcome. This case report exemplifies the importance of early diagnosis and treatment of ruptured HCC.
\end{abstract}

Key words: Hepatocellular cancer; rupture; transarterial embolization

Address for correspondence:

Dr. Hamid Shaaban, Department of Internal Medicine, Hematology and Oncology, St. Michael's Medical Center, Newark, NJ 07102, USA.

E-mail: hamidshaaban@gmail.com

Received: 20-06-2015, Accepted: 19-11-2015

\section{INTRODUCTION}

Hepatocellular carcinoma (HCC) is the most common primary malignant tumor of the liver, and one of the leading causes of death in patients with cirrhosis. Spontaneous rupture is a fatal complication of HCC that occurs in 3-15\% of cases and is associated with worse short- and long-term prognosis. ${ }^{[1-3]}$ In this case report, we are presenting a case of a 64-year-old female with a history of chronic hepatitis $\mathrm{C}$ infection who presented with abdominal pain and was found to have a ruptured HCC. She was managed with the two-stage therapeutic approach first using transarterial embolization (TAE) to provide adequate hemostasis and then surgical resection with an excellent outcome. This case report exemplifies the importance of early diagnosis and treatment of ruptured HCC.

\section{CASE REPORT}

We are reporting a case of a 64-year-old female with past medical history of hypertension and hepatitis $\mathrm{C}$, who was diagnosed and treated in the year 2000 with interferon and ribavirin. She presented to our emergency department

\begin{tabular}{|l|c|}
\hline \multicolumn{3}{|c|}{ Access this article online } \\
\hline \multirow{2}{*}{$\begin{array}{l}\text { Website: } \\
\text { http://hrjournal.net }\end{array}$} & Quick Response Code \\
\hline & DOI: \\
10.4103/2394-5079.171207 &
\end{tabular}

with worsening right upper abdominal pain for the last few months; the symptoms continued to progressively get worse until her presentation to the emergency department. Initial vital signs showed blood pressure of 140/76 $\mathrm{mmHg}$, pulse rate of 74 beats/min, respiratory rate of 18 breaths/min, and oxygen saturation of $98 \%$ on room air. Physical examination showed significant right upper quadrant tenderness, soft abdomen with no guarding or rigidity and active bowel sounds, normal heart sounds with no murmurs or added sounds, and normal breath sounds. Initial lab results showed a white blood cell count of $7.4 \mathrm{k} / \mu \mathrm{L}$, hemoglobin of $14.2 \mathrm{~g} /$ $\mathrm{dL}$, hematocrit of $42.8 \%$, platelets of $177 \mathrm{k} / \mu \mathrm{L}$, creatinine of $0.89 \mathrm{mg} / \mathrm{dL}$, aspartate aminotransferase of $30 \mathrm{IU} / \mathrm{L}$, alanine aminotransferase of $29 \mathrm{IU} / \mathrm{L}$, alkaline phosphatase of 63 , total bilirubin of 0.8 , prothrombin time of $13.6 \mathrm{~s}$, partial thromboplastin time of $25.7 \mathrm{~s}$, international normalized ratio of 1.3 , albumin of $3.9 \mathrm{~g} / \mathrm{dL}$, alpha-fetoprotein (AFP) of 1380 $\mathrm{ng} / \mathrm{mL}$, and hepatitis $\mathrm{C}$ antibodies were positive, but with an undetectable viral load, hepatitis B antibodies and surface antigen were negative.

An abdominal ultrasound showed a $7 \mathrm{~cm} \times 6 \mathrm{~cm}$ mass in the right hepatic lobe, abdominal computed tomography (CT)

This is an open access article distributed under the terms of the Creative Commons Attribution-NonCommercial-ShareAlike 3.0 License, which allows others to remix, tweak, and build upon the work non-commercially, as long as the author is credited and the new creations are licensed under the identical terms.

For reprints contact: service@oaepublish.com

How to cite this article: Hawatmeh A, Jumean K, Arqoub AA, Shaaban $\mathrm{H}$. Spontaneous rupture of hepatocellular carcinoma. Hepatoma Res 2016;2:103-6. 
scan with contrast and triple phase abdomen CT scan were done for better visualization of the mass which showed a $7.2 \mathrm{~cm} \times 5.8 \mathrm{~cm}$ heterogeneous enhancing mass in the sixth segment of the liver, with a pseudocapsule bulges on the liver capsule, which has an adjacent small $6 \mathrm{~cm} \times$ $3 \mathrm{~cm}$ accumulation of complex fluid that likely represents a ruptured HCC and less likely a benign liver tumor with regional hematoma, the liver was abnormal in appearance with nodular contour suggestive of underlying cirrhosis/ fibrosis [Figures 1 and 2].

Gastroenterology, hepatobiliary surgery, and interventional radiology (IR) were consulted, after that and while the patient was being evaluated, her hemoglobin level dropped to 12.2 $\mathrm{g} / \mathrm{dL}$ and she became more tachycardic. At that time, the impression was that the patient has a ruptured HCC, and the decision was to do an IR-guided bland embolization of the tumor. The embolization was done using polyvinyl alcohol particles. After that, the patient remained hemodynamically stable. Later, she underwent resection of the tumor and the sixth segment of the liver, during surgery there was no evidence of spread of the tumor outside the liver.

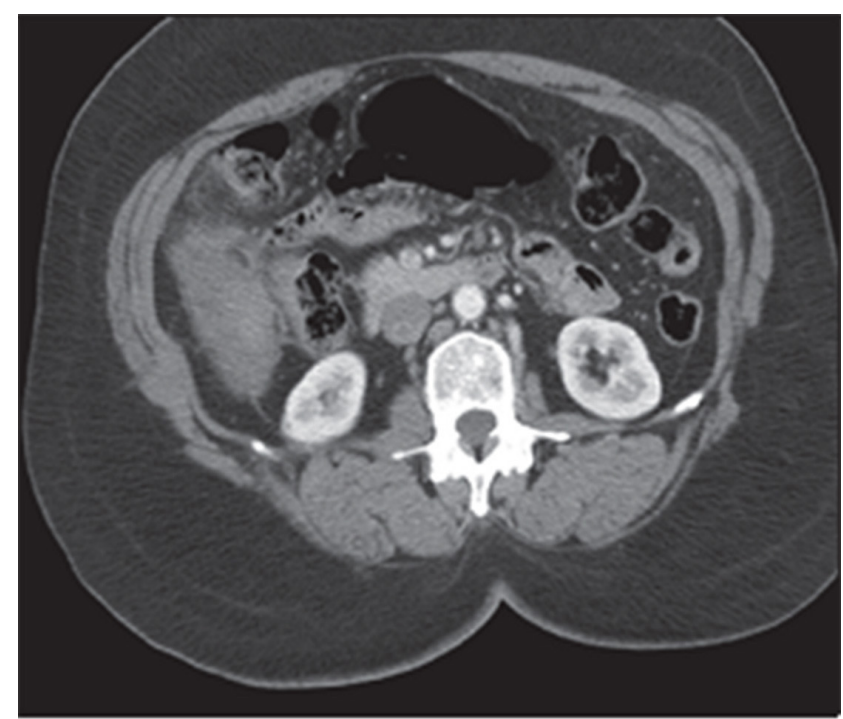

Figure 1: Computed tomography scan revealing evidence of hepatocellular cancer

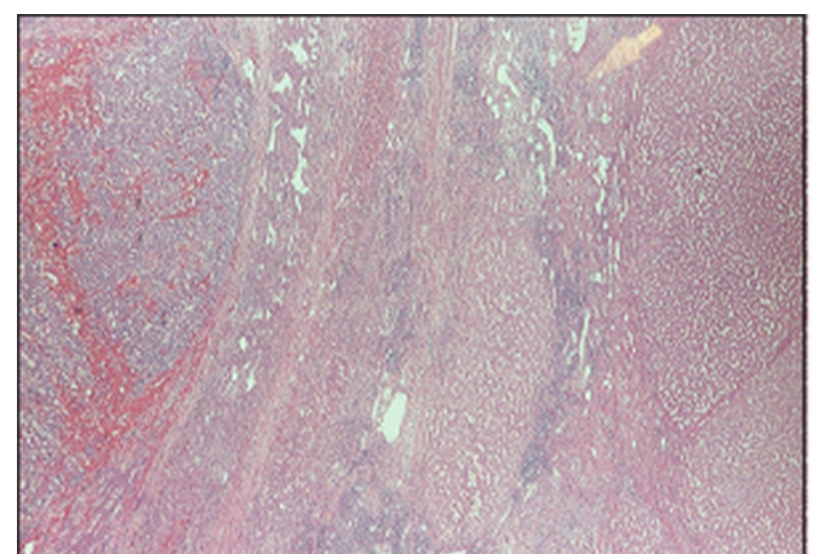

Figure 3: Histopathology of liver tissue revealing a trabecular and pseudoglandular growth pattern with foci of necrosis and hemorrhage
The pathology report showed a $6.5 \mathrm{~cm} \times 6.1 \mathrm{~cm} \times 6.0 \mathrm{~cm}$ moderately differentiated HCC with a trabecular and pseudoglandular growth pattern with foci of necrosis and hemorrhage and negative surgical margins, it also showed vascular invasion of the portal triad and diffuse macronodular cirrhosis [Figures 3 and 4]. At this point, the decision was made to follow-up the patient closely with AFP, liver function test, and imaging studies every 3 months for the first 2 years. Follow-up AFP about 1 month after surgery was $54.4 \mathrm{ng} / \mathrm{mL}$ and $4.8 \mathrm{ng} / \mathrm{mL}$ after 3 months.

\section{DISCUSSION}

HCC is the most common primary malignant tumor of the liver; it is also known to be the fifth most common cancer and the third most common cause of cancer-related death worldwide. ${ }^{[1,2]}$ HCC is a hypervascular tumor that mostly occurs in the settings of liver cirrhosis, and it is one of the leading causes of death in patients with cirrhosis.

Spontaneous rupture is a major life-threatening complication of HCC that occurs in $3-15 \%$ of cases with geographical differences among Western, Asian, and African countries, where HCC is more frequent..$^{[3]}$ The incidence of HCC is on decline due to early detection and screening.

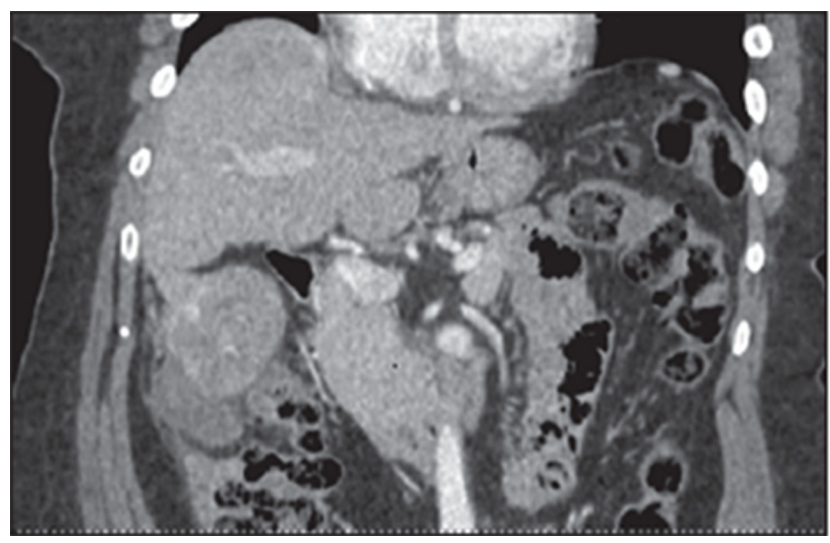

Figure 2: Computed tomography scan confirming evidence of hepatocellular cancer with regional hematoma

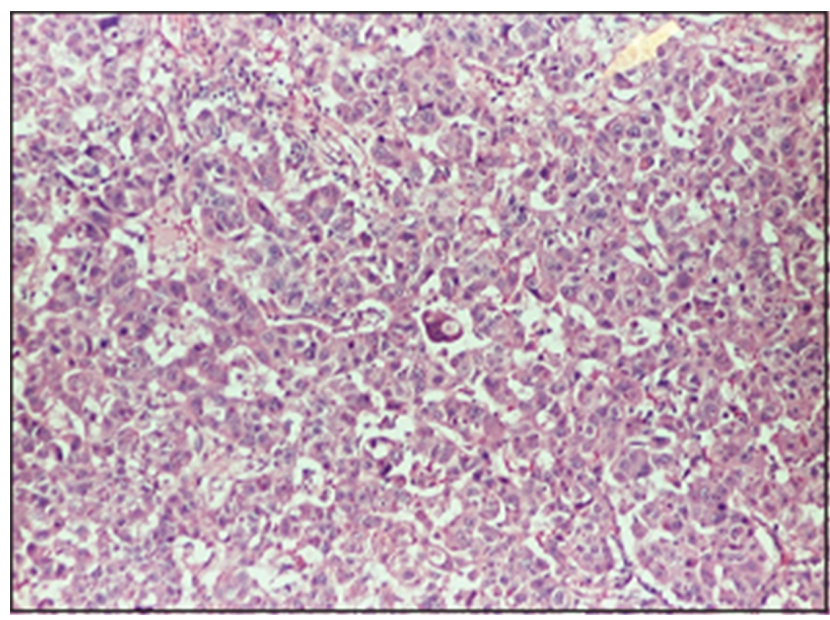

Figure 4: Histopathology of resected hepatic tumor 
Generally, short- and long-term survival rates after ruptured HCC are worse compared to non-ruptured HCC patients. Spontaneous rupture is considered the third leading cause of HCC-related death after tumor progression and liver failure, with an associated mortality that is even higher than ruptured esophageal varices. ${ }^{[4]}$

The exact mechanism of spontaneous rupture of HCC is not clearly known at this time, but it is believed to be related to a tear in the tumor surface or rupture of a feeding artery..$^{[5]}$ Risk factors that could be responsible for HCC rupture include subcapsular location, rapid growth of the tumor with necrosis, and erosion of vessels and blunt abdominal trauma, especially with superficial tumors. ${ }^{[6,7]}$

The usual symptoms of spontaneous rupture are right upper quadrant or epigastric pain, and when the lesion is more peripheral and located on the free surface of the liver, it might be associated with signs of shock and peritoneal irritation due to hemoperitoneum. Peritoneal irritation due to bleeding is not as common in cases of rupture of a deeper lesion, which does not interrupt the liver capsule. In addition to pain and hemorrhagic shock, there is also a risk of peritoneal seeding of cancer cells, which worsen the prognosis. The diagnosis can be confirmed by the presence of hemoperitoneum on abdominal paracentesis. Ultrasonography may demonstrate a hepatic tumor and ascites, the rupture site appears as a hyperechoic area around the tumor, CT is valuable in showing the tumor with a high attenuation close to it, which represents acute blood clotting. Conventional angiography may reveal extravasations of contrast from the tumor. Zhu et al. ${ }^{[8]}$ reported that the positive rate of correct diagnosis was $86 \%$ with paracentesis, $66 \%$ by ultrasonography, $100 \%$ by CT, and $20 \%$ by angiography.

Treatment of spontaneous rupture of HCC is dependent on the pre-ruptured liver function and severity of bleeding, liver resection is the only curative option for ruptured HCC and the first step of treatment is resuscitation and stabilization of the patients..$^{[9-11]}$

The open surgical method was the mainstay of treatment for hemostasis in the period from the 1960s to the 1980s. Various surgical procedures, including perihepatic packing, suture plication of bleeding tumors, hepatic artery ligation, and liver resection, were reported to be effective in hemostasis. ${ }^{[10-13]}$ Open surgical procedures achieved a high rate of hemostasis but were associated with a high in-hospital mortality rate. With the introduction of TAE and transarterial chemoembolization (TACE), TAE has been increasingly used for hemostasis in ruptured HCC. Now, open surgical hemostasis becomes a second-line treatment when TAE fails or it is not available. However, it is still regarded as a reliable method for hemostasis, and permits consideration for resection of the tumor at the same time..$^{[4]}$
The two-stage therapeutic approach to manage ruptured HCC consists of initial management by conservative method, hemostasis by TAE or surgical means, and followed by second-stage hepatic resection or TACE. ${ }^{[7,9]}$ Previous studies suggested that multidisciplinary management with TAE and postponed surgery in selected patients improve the short-term mortality. ${ }^{[7]}$ If the patient's conditions allow, a two-staged approach involving TAE for hemostasis followed by staged hepatectomy is preferred over emergency hepatectomy. This approach permits to stabilize the patient, assess the liver function, and stage cancer to better plan the surgical resection. Emergency liver resection can achieve hemostasis and provide a definitive treatment in a single operation. However, onestage hepatectomy is only recommended for patients with preserved liver function (Child-Pugh Classes A and B) and resectable tumors. ${ }^{[12-14]}$

Conser vative treatment is recommended for patients who are hemodynamically stable at initial presentation. TAE is the first choice of treatment for unstable patients with continuous intra-abdominal hemorrhage, TAE is thought to be the ideal treatment because it is simple and effective with a success rate of about $90 \% .{ }^{[0]}$ Definitive treatment of HCC should follow the initial recovery from ruptured HCC. Patients with preser ved liver function and resectable tumors should be considered for curative hepatic resection if a lowrisk curative resection is possible for patients with Child-Pugh Classes $A$ and $B .^{[10-13]}$ TAE as a palliative procedure is indicated when the liver function is compromised or in the case of multifocal bilobar HCC. Long-term sur vival is correlated with the stage of the disease, its local spread after rupture, and the residual hepatic function. ${ }^{[9-12]}$

In summary, HCC has a tendency to rupture spontaneously, which may lead to a life-threatening condition. Though recently TAE followed by a second-stage resection has been the first choice of treatment, laparotomy is still a reliable method for hemostasis and permits consideration for resection of the tumor at the same time. In the presented case, the two-stage therapeutic approach was used, utilizing a multidisciplinary team approach consisting of gastroenterology, hepatobiliary surgery, and IR consultants. Our patient was first managed with TAE to achieve hemodynamic stability and after that she underwent resection of the tumor with excellent outcomes.

To our knowledge, until now, there has been no prospective randomized controlled trial or well-designed comparative study to find out which is the best method of hemostasis. Most evidence comes from cohort series; therefore, more research is needed in this field.

\section{Financial support and sponsorship}

Nil.

\section{Conflicts of interest}

There are no conflicts of interest. 


\section{REFERENCES}

1. Bosch FX, Ribes J, Cléries R, Díaz M. Epidemiology of hepatocellular carcinoma. Clin Liver Dis 2005;9:191-211.

2. Jemal A, Bray F, Center MM, Ferlay J, Ward E, Forman D. Global cancer statistics. CA Cancer J Clin 2011;61:69-90.

3. Vergara V, Muratore A, Bouzari H, Polastri R, Ferrero A, Galatola G, Capussotti L. Spontaneous rupture of hepatocellular carcinoma: surgical resection and long-term survival. Eur J Surg Oncol 2000;26:770-2.

4. Lai EC, Lau WY. Spontaneous rupture of hepatocellular carcinoma: a systematic review. Arch Surg 2006;141:191-8.

5. Kanematsu M, Imaeda T, Yamawaki Y, Seki M, Goto H, Sone Y, Iinuma G, Mochizuki R, Doi H. Rupture of hepatocellular carcinoma: predictive value of CT findings. AJR Am J Roentgenol 1992; 158:1247-50.

6. Chearanai O, Plengvanit U, Asavanich C, Damrongsak D, Sindhvananda K, Boonyapisit S. Spontaneous rupture of primary hepatoma: report of 63 cases with particular reference to the pathogenesis and rationale treatment by hepatic artery ligation. Cancer 1983;51:1532-6.

7. Buczkowski AK, Kim PT, Ho SG, Schaeffer DF, Lee SI, Owen DA, Weiss AH, Chung SW, Scudamore CH. Multidisciplinary management of ruptured hepatocellular carcinoma. $J$ Gastrointest Surg 2006;10:379-86.

8. Zhu LX, Wang GS, Fan ST. Spontaneous rupture of hepatocellular carcinoma. Br J Surg 1996;83:602-7.

9. Rossetto A, Adani GL, Risaliti A, Baccarani U, Bresadola V, Lorenzin D, Terrosu G. Combined approach for spontaneous rupture of hepatocellular carcinoma. World J Hepatol 2010;2:49-51.

10. Recordare A, Bonariol L, Caratozzolo E, Callegari F, Bruno G, Di Paola F, Bassi N. Management of spontaneous bleeding due to hepatocellular carcinoma. Minerva Chir 2002;57:347-56.

11. Yeh CN, Lee WC, Jeng LB, Chen MF, Yu MC. Spontaneous tumour rupture and prognosis in patients with hepatocellular carcinoma. $\mathrm{BrJ}$ Surg 2002;89:1125-9.

12. Chiappa A, Zbar A, Audisio RA, Paties C, Bertani E, Staudacher C. Emergency liver resection for ruptured hepatocellular carcinoma complicating cirrhosis. Hepatogastroenterology 1999;46:1145-50.

13. Tanaka A, Takeda R, Mukaihara S, Hayakawa K, Shibata T, Itoh K, Nishida N, Nakao K, Fukuda Y, Chiba T, Yamaoka Y. Treatment of ruptured hepatocellular carcinoma. Int J Clin Oncol 2001;6:291-5.

14. Ribeiro MA Jr, Fonseca AZ, Chaib E, D'Ippolito G, Carnevale FC, Rodrigues JJ, Saad WA. An unusual approach to the spontaneous rupture of hepatocellular carcinoma. Hepatogastroenterology 2007;54:1235-8. 